\title{
THE CONSTRUCTION OF NATIONAL IDENTITY THROUGH CYBERNETIC PROCESS: THE EXAMPLE OF "K'NA" DANCE EVENT IN GREEK AND TURKISH THRACE
}

\author{
ELENI FILIPPIDOU ${ }^{1}$, MARIA KOUTSOUBA ${ }^{2}$, VASSILIKI LALIOTI ${ }^{3}$, VASSILIS \\ LANTZOS $^{4}$ \\ 1. School of Physical Education and Sports Science,National and Kapodistrian University of Athens, Greece \\ 2. School of Physical Education and Sports Science,National and Kapodistrian University of Athens, Greece \\ 3. Department of music studies, National and Kapodistrian University of Athens, Greece \\ 4. School of Physical Education and Sports Science, National and Kapodistrian University of Athens, Greece
}

(c) 2019 Eleni Filippidou, Maria Koutsouba, Vassiliki Lalioti, Vassilis Lantzos

This is an open access article distributed under the Creative Commons Attribution-NonCommercial-NoDerivs license (http://creativecommons.org/licenses/by-nc-nd/3.0/)

DOI: $10.1515 /$ eras-2019-0002

\begin{abstract}
The research field of this paper is the area of Thrace, a large geopolitical-cultural unit that was divided - due to political reasons - in three subareas distributed among three different countries: Bulgaria, Turkey and Greece. A dance event that used to take place before the border demarcation but is still performed in the Greek and Turkish Thrace is that of "K'na", a wedding dance event danced by the people of both border areas, despite of the changes in their magical-religious beliefs and the changes brought by socio-economic and cultural development. In particular, the aim of this paper is the study of the "construction" of the national identity of inhabitants both of Greek and Turkish Thrace, as this is manifested through the dance practice within the wedding event of "K'na", through the lens of sociocybernetics. Data was gathered through ethnographic method as this is applied to the study of dance, while its interpretation was based on sociocybernetics according to Burke's identity control theory. From the data analysis, it is showed that the "K'na" dance in Greek and Turkish Thrace constructs and reconstructs the national identity of the people who use them as a response to the messages they receive via the communication with "the national others". In conclusion, the "construction" of the identity results from a continuous procedure of self-regulation and self-control through a cybernetic sequence of steps.
\end{abstract}

\section{Keywords}

sociocybernetics, identity control theory, “K'na” dance event, Greek Thrace, Turkish Thrace

\section{Introduction}

Dance is a kind of human behavior, which, based on the discussions to date, has been defined as an action that includes meaning, symbolism, esthetics and social meaning and it is expressed through kinetic and symbolic activity of the body. During the last decades, studies on Greek traditional dance have focused on assessing the connection between dance and cultural identity (Chilari, 2009; Cowan, 1998; Dimopoulos, 2011, 2017; Dimopoulos, Tyrovola, \& Koutsouba, 2009; Filippidou, 2011, 2013, 2018; Foutzoulas, 2016; Kalogeropoulou, 2013; Koutsouba, 1991, 1997; Manos, 2002; Margari, 2004; Panopoulou, 2001; Papakostas, 2007; Sarakatsiannou, 2011) since dance is a kind of cultural knowledge (Sklar, 1991) and it can externalize a particular content and abstract meanings. As follows, cultural practices, including music, song and dance, are integrated within a socioeconomic, cultural and ideological background and, in principle, they constitute mechanisms for the 
configuration of the cultural identity, through a variety of transformations.

However, dance, as a kind of human behavior, also forms an integral part of the overall structure of a cultural communicative system. According to Paschalidis (2000), communication is a significant function for the human existence as it has been the basic element for the formation of human societies and the creation of civilizations. Therefore, communication not only provides a sense of citizenship to individuals and social groups, but also the perception that they belong to a socio-cultural unit, in other words to a common identity (Vrizas, 2005). Hecht et al. define communication as a way of creating identity. In other words, Hecht et al. sustain that identity is a communicative construction. An identity is constructed when people or groups communicate, that is to say, when they interact with the "others". In this way the people or the groups involved in the communication process internalize the reactions or opinions of the "others" during the relational interaction (Watzlawick, Beavin, \& Jackson, 1967) and they, in turn, express them and respond to the "others" by projecting their identity.

According to the cybernetic tradition of communication, when two people communicate [...] they define their relationship by the ways they interact (Watzlawick, Beavin, \& Jackson, 1967). In the cybernetic approach, relationships that are produced in a group consist of patterns of interaction "in which individuals' words and actions affect the responses of others" (Littlejohn \& Foss, 2012). People that belong to a group continually adapt their actions to the reactions of "others" based on the feedback they receive from them. Therefore, within cybernetics, communication is understood as a system of parts or variables, which influence one another, shape and control the character of the overall system, and like any other organism achieve both balance and change. Taking all the above into consideration, one can comprehend that in the cybernetic model of communication particular emphasis is placed not on the message per se but on the aims that are pursued with the transmission of it (McQuail \& Windahl, 1993), and the relationships that are shaped from the accomplishment of the aims among the communicating groups. Based on the above we could say that cybernetics constitutes the interpretation base both for individual and collective identification.

The research field of this paper is the area of Thrace, a large geopolitical-cultural unit thaw was divided - due to political reasons - in three subareas distributed among three different countries: Bulgaria, Turkey and Greece. A dance event that used to take place before the border demarcation but is still performed to date in the Greek and Turkish Thrace is that of "K'na". "K'na" is a wedding dance event which is danced to date by the people of both border areas in spite of the vanishment of their magical-religious beliefs and the changes brought by socioeconomic and cultural development.

In particular, the aim of the paper is the study of the "construction" of the national identity of inhabitants of Greek and Turkish Thrace, as this is manifested through dance practice within the wedding event of "K'na", through the lens of sociocybernetics. In order to achieve this, research in two communities took place, namely Adrianoupoli in Turkish Thrace and Nea Vyssa in Greek Thrace. More specifically, the residents of the Greek community of Nea Vyssa relocated to the Greek Thrace from the area of Adrianoupoli after the Treaty of Lausanne. Because of that, and along with the urban character of the community since it is one of the urban communities of Thrace, the two aforementioned communities have been chosen for the needs of this research.

\section{Methodology}

The methodological process consisted of three steps, namely data collection, analysis and interpretation. Data was gathered through the ethnographic method (Gkefou-Madianou 1999; Lydaki, 2001) as this is applied to the study of dance (Buckland, 1999; Giurchescu \& 
Torp, 1991; Sklar, 1991; Koutsouba, 1991, 1999) and is based on primary and secondary sources. Primary sources refer to data gathered through in situ research that was carried out at the region of Thrace and, particularly, at the community of Nea Vyssa from December 2005 up to July 2017 and to Adrianoupoli in Turkish Thrace from December 2014 up to July 2017. Primary sources refer to the data coming from in-situ research, through interviews (open-type questions for semi-structured interview and unstructured interview), and the participant observation combined with simultaneous audio and video recording of the inhabitants of the community.

In addition, oral history was used as a method, through which everyday memory is projected as a quest of social history (Thomson, 2002). The overall course of field research was performed by the dual experience of the local culture with reference both to the habitants of this particular community (carriers of the local culture), as well as to the researchers (Erixon, 1967). Secondary sources refer to the review and use of the existing literature and were based on the principles of archival ethnography (Gkefou-Madianou, 1999; Stocking, 1992) and historical research (Adshead \& Layson 1998).

For collection, presentation and data analysis Geertz's model of "thick description" (2003) was adopted, while for recording the different types of "K'na" dance, the dance notation system of Laban was used (Labanotation) (Hutchinson, 1977; Koutsouba, 2005, 2014) as well as the Laban System of Effort. For the comparisons, comparative method was used (Holt, \& Turner, 1972; Ogurchov, 1983). Finally, the analytical meanings of "myself"/"someone else" and "us"/“others" (Gkefou-Madianou 1999; Koutsouba 1997) that signify the identity as a cultural and social structure were the means of making the voices of these people heard, giving them the opportunity to become informants, while the data interpretation was based on the theoretical perspective of sociocybernetics, according to the identity control model that Burke (1991a, b) proposed.

In particular, urged by cybernetics theory, Burke (1991) structured a model of identity control (Identity Control Theory - ICT), in which the process of developing an identity is a result of a control process (Burke, 1980, 1991b,1995, 1996, 1997; Burke \& Gekas 1994; Burke \& Cooper 2000, Burke \& Stets 1994; Ellestad \& Stets, 1998; Simmons, Smith, Erez, Burke \& Pozos, 1998; Stets, 1993, 1995). More analytically, Burke (1991) considers that the identity consists of a set of meanings, which include symbolic and non-symbolic components (Burke \& Freese, 1989). These meanings are applied to the self in a social role or situation, defining what it means to be who one is (Burke \& Tully, 1977). This set of meanings functions as a point of reference, namely as an identity standard.

According to the Burke model, when an identity is activated a feedback loop is established, which consists of four structural components (Stokes, 2006, 2007) which are: a) a reference standard or setting [a set of self-meanings], b) an input from the environment or social situation including one's reflected appraisals, c) a process that compares the input with the standard via the operation of a comparator and d) an output to the environment, generated by the comparison and which is then the source of behaviors intended to bring one's perceptual inputs into an identity relationship with one's reference standards (Burke, 1991) (see Figure 1). 


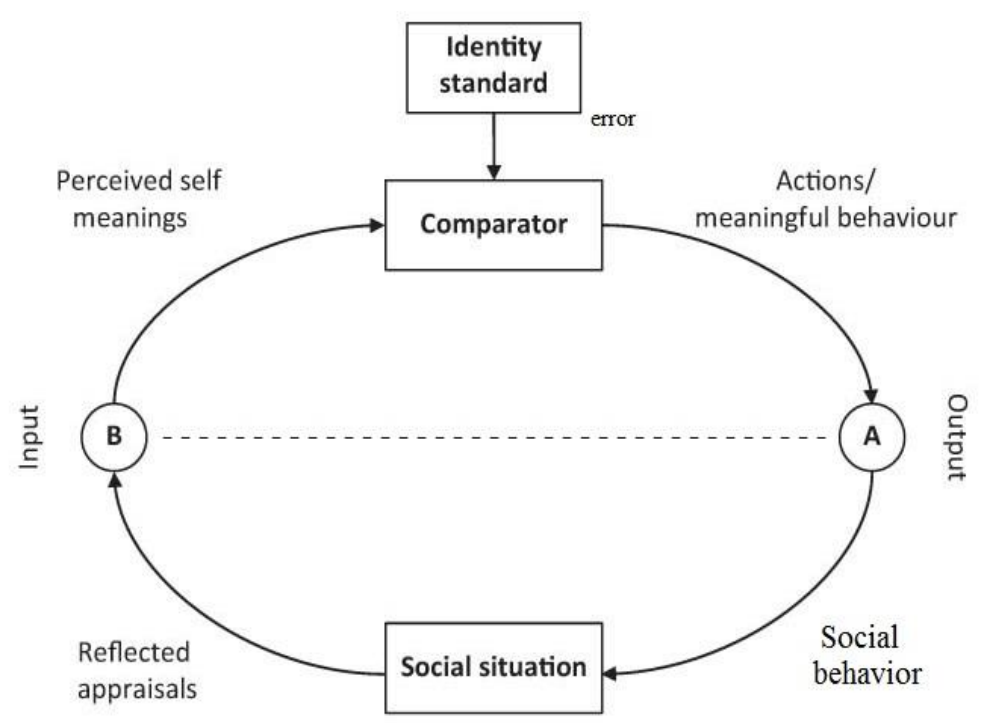

Figure 1: Identity Control Theory-ICT

(Burke, 1991)

This model functions by converting the output, meaning the behavior in a social situation, with the aim to change the incoming information (input) that concern reflected appraisals of self. This is done in order to match internal standards (Burke, 1991), meaning it tries to self-adjust the perceptual input it receives.

\section{Thrace: History and ethnographic context}

Thrace is an area of the Balkan Peninsula, in the northeast of Greece. Until its trisection that was completed in 1923, following the Treaty of Lausanne, it constituted a large geopolitical-cultural unit (see Picture 1). This geographical area stretched from the Strymon river in the west up to the Black Sea in the east and from the Aegean Sea and the Propontida southwards up to the Danube river northwards in the ancient times (Chatzopoulos, 2015).

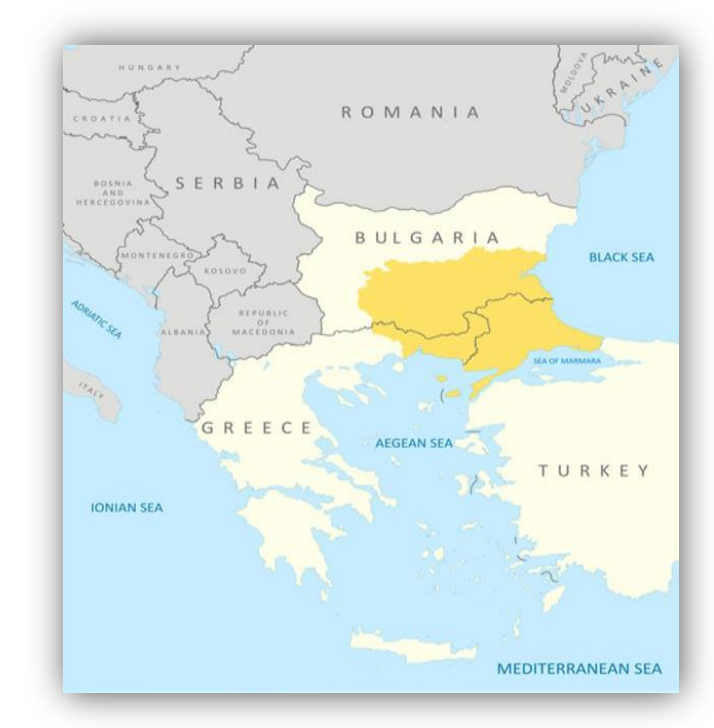

Picture 1: The historical area of Thrace

(http://www.wikiwand.com/el/\% CE\% 98\% CF\%81\% CE\% AC\% CE\%BA\% CE\%B7)

Historically, Thrace was an area of wars ever since the ancient times, due to its 
geographical position between Europe and Asia. These conflicts increased in number especially during the Byzantine era. The extension of Christianity and the foundation of Constantinople that became the capital city of the Eastern Roman Empire in 330 AD, was a turning point in history as Thrace becomes the center of the Byzantine Empire. Around 600 $\mathrm{AD}$, destructive invasions of the Slavs took place, while in $1453 \mathrm{AD}$, following the fall of Constantinople by the Ottomans, the whole area of Thrace passes on to the Ottoman ruling, submitting to the Turks along with all the other Byzantine provinces (Greek Parliament, 2000).

In 1878, an autonomous Greek area was established on the north of the mountain range of Rhodopes, within the borders of the Bulgarian country, which became known to Greeks as East Romelia. In 1885, East Romelia was violently annexed to the Bulgarian country (Greek Parliament, 2000). In 1920, the great powers of the times: Great Britain, France, Italy and Japan, assigned a large part of Thrace to Greece. However, two years later, Greece had to assign a part of Thrace to Turkey due to the Asia Minor catastrophe. Due to the aforementioned, more than 200,000 Greeks who lived there had to abandon their ancestral homes and seek refuge in present day of Greek Thrace, Macedonia, as well as in other parts of Greece. Therefore, the trisection of the biggest area of Thrace was formally completed with the Treaty of Lausanne in 1923 (Parliamentary Papers, 1923) and was distributed in three countries, Bulgaria, Turkey and Greece to date.

Turkish Thrace (in the Turkish language: Trakya and in Bulgarian: Източна Тракия) lies in the eastern part of historical or greater Thrace. Turkish Thrace is also called European Turkey and comprises of Constantinople (Instabul), Raidestos (Tekirdağ), Tsorlou (Çorlu), Arkadioupoli (Lüleburgaz), Saranta Ekklisies (Kırklareli) and Adrianoupoli (Edirne). Adrianoupoli was founded and named after the Roman Emperor Hadrian in 125 AD. The Turkish name of the city is Edirne, which is a corruption of "Adrinou", in other words "Adrianos", as the city was named in the 14th century. Hadrian turned Adrianoupoli into the capital of the Roman province of Thrace and in 1362 it was proclaimed as the capital city of the Ottoman Empire after the conquest of Sultan Murat A.

Up to the beginning of the 20th century, it was a multicultural area inhabited by Bulgarians, Armenians and Jews. The biggest population groups were those of Turks and Greeks. The Greeks lived there up to 1923 when the Treaty of Lausanne was signed along with the Karagacac protocol that demarcated the borders and established the exchange of population between the two countries. One of the communities that moved to the Greek area of Thrace was Bosna or Bosnohori. The residents of Bosna had to relocate $4 \mathrm{Km}$ south next to the Turkish-Greek borders and settle in the Ahırköy settlement that was left in Greece. In 1920, it was renamed to Stavlohori, in 1930 to Achirohori and finally, in 1932 to Nea Vyssa (Filippidou, 2010).

\section{Some remarks on the "K'na" dance event}

"K'na" is a wedding dance event particularly popular within the communities of Evros, especially those originating from the part of Thrace that now belongs to Turkey, such as Nea Vyssa (Filippidou, 2010, 2018). This wedding dance event takes place the night before the wedding at the bride's house (Filippidou, 2010, 2018). More specifically, on that same night, the night before the wedding ceremony, a farewell party is held at the house of the bride as well as at the house of the groom. At the groom's house his family celebrates the last day of the groom-to-be but now unmarried lad. At the bride's house the night is more emotionally charged since it is the last night of the bride celebrating with her friends and family before moving to her husband's home. When all the guests arrive and the party begins, the bride's mother in law accompanied by groom's relatives bring her "the Baxisia", in other words, her 
presents. Among those there is a small plate with some henna. After they dance "the Baxisia" dance and then give them to the bride, they take "the Baxisia" for the groom from the relatives of the bride, they return to the grooms' house and continue the party there.

Later on, just before the end of the party, three newlywed girls (that have been married just once) whose both parents were still in life, prepare the "K'na", that is to say, the henna, in a brass or earthenware plate, by using their right hands. They add water, flour and wine to this and place three lit candles on the top. Next, they tie a red thread around the candles, while during the preparation of the henna the relatives sing three songs suitable for this special occasion. The songs played are about emigration due to the fact that the bride is soon to leave her family and home and live with her husband and his family. After the kna preparation, the bride's ring finger and the little finger are painted by a female member of her family. They are painted up to the second phalanx and then tied with two white handkerchiefs or cloths. When this ritual is completed dancing begins with the first one in the line holding in his/her right hand the sacred object of the ceremony which is the three lit candles (see Picture 2) (Filippidou, 2010, 2018).

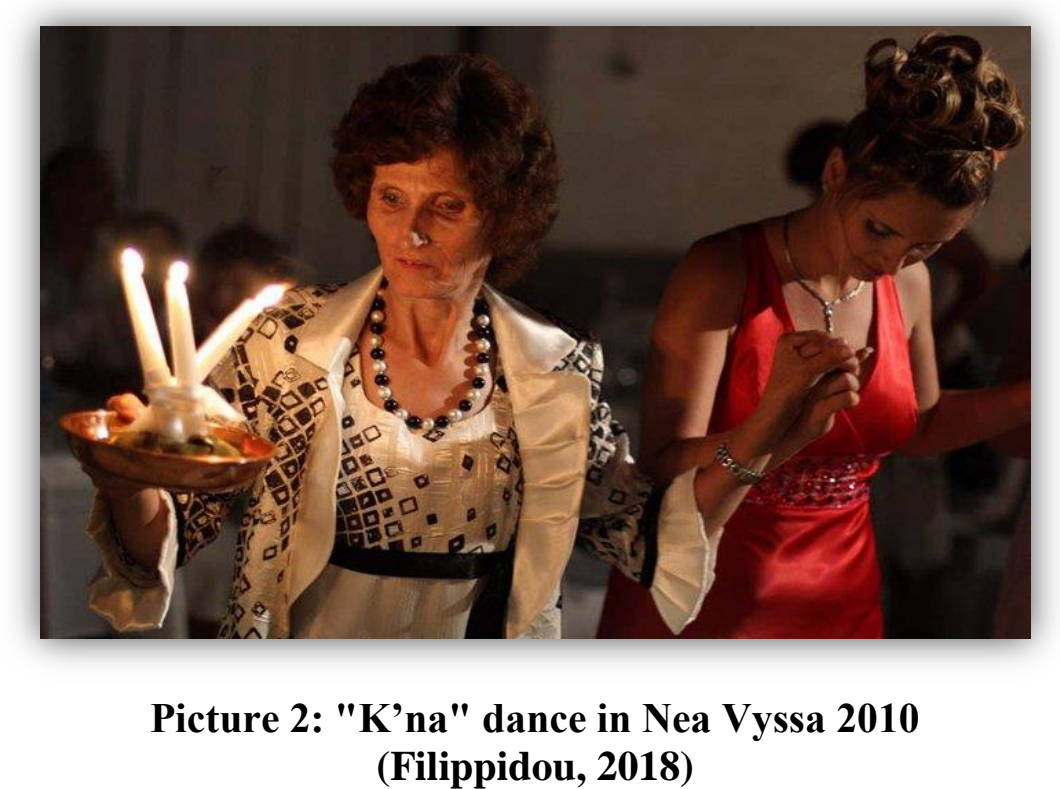

The "K'na" dance event is performed in the same way in both under study communities. However, in Nea Vyssa the "K'na" dance paradoxically exists in three different dance compositions. The two of them originate from the first-generation refugees while the third one from the second-generation refugees (Filippidou, 2018). More specifically and according to the informants, one choreographic composition refers to the dance patterns that the residents of the community brought with them when they came to their new homeland. This choreography consists of a unilateral style (see Figure 2). The second choreography consists of a bilateral style ("sta tria" and "sta dyo" style) that was also danced by the firstgeneration refugees, who added a second dancing phrase to the " $\mathrm{K}$ 'na" dance, in order this to look similar to the one that was performed by the locals.

Finally, the third choreographic composition refers to the second generation of refugees who totally omitted the first phrase of the "K'na" dance, according to Junta's suggestions (see Figure 4) (Filippidou, 2018). On the other hand, in Edirne there is only one choreography of the "Kna" dance, which remains unchanged until today (see Figure 5).

Based on the above, a number of questions arise at this point such as: What was the reason that triggered the performance of various versions of the same dance in that 
community? On the contrary, what was the reason that choreographic diversity did not exist within the community of Edirne?

\author{
"K'na" dance \\ first generation refugees
}

Labanotation

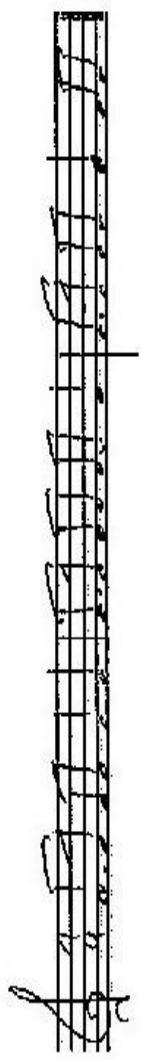

3

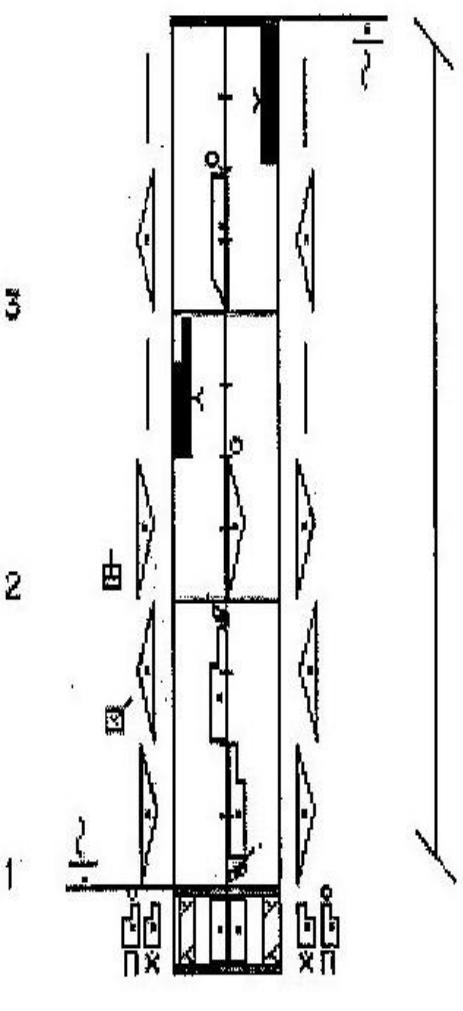

$$
4 / 4[=\text { 由 } \therefore \text { Ob }
$$

Effort

$k$

Figure 2: "K'na" dance of the first generation of refugees in Nea Vyssa (Filippidou, 2018) 

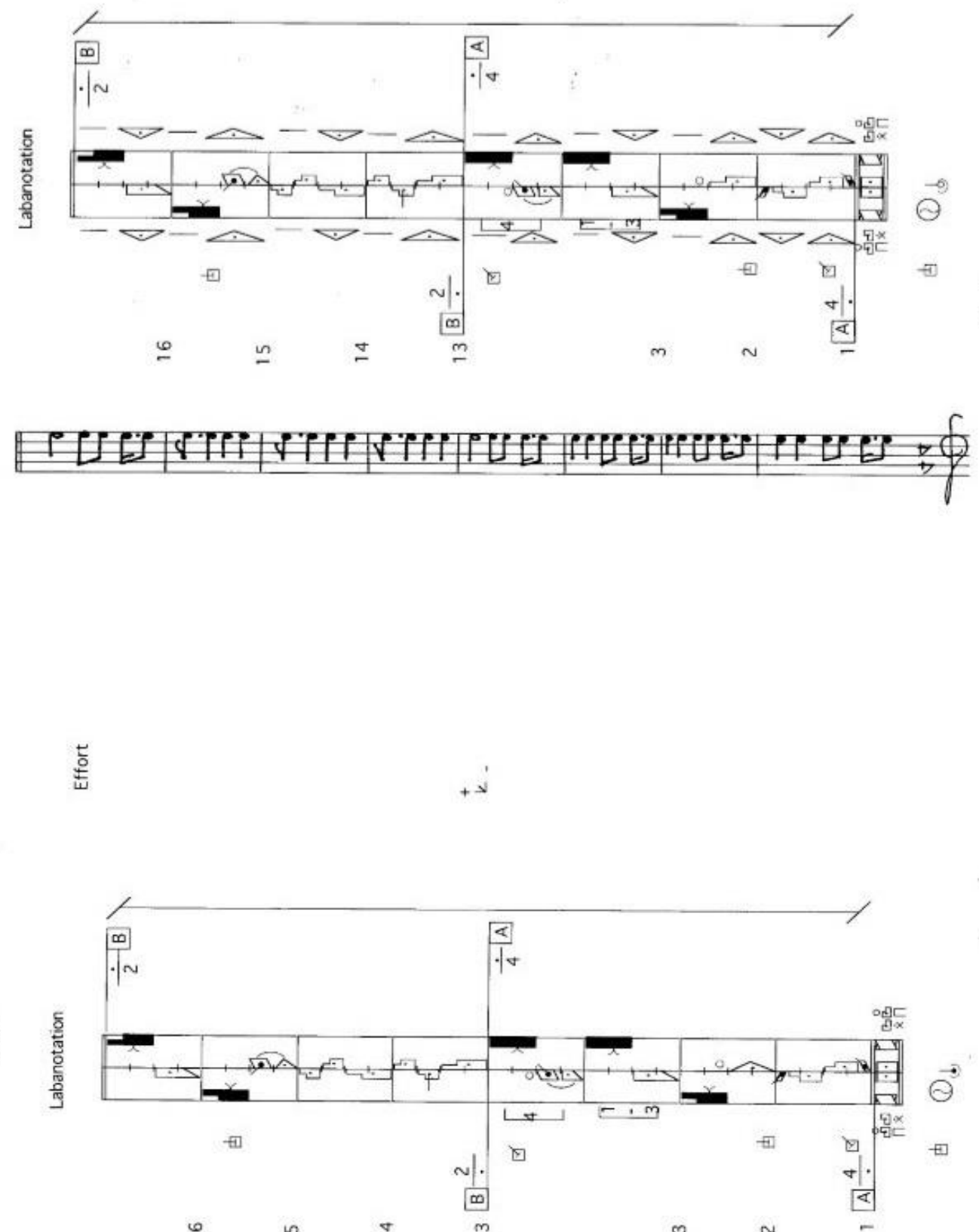

$\because \stackrel{\square}{-}$

$\stackrel{m}{-}$

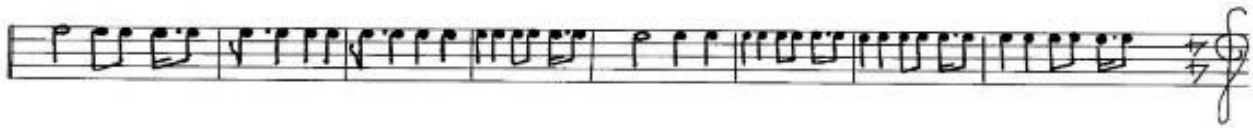

Figure 3: "K'na" dance of the first generation of refugees in Nea Vyssa after the settlement in Greek territory

(Filippidou, 2018) 


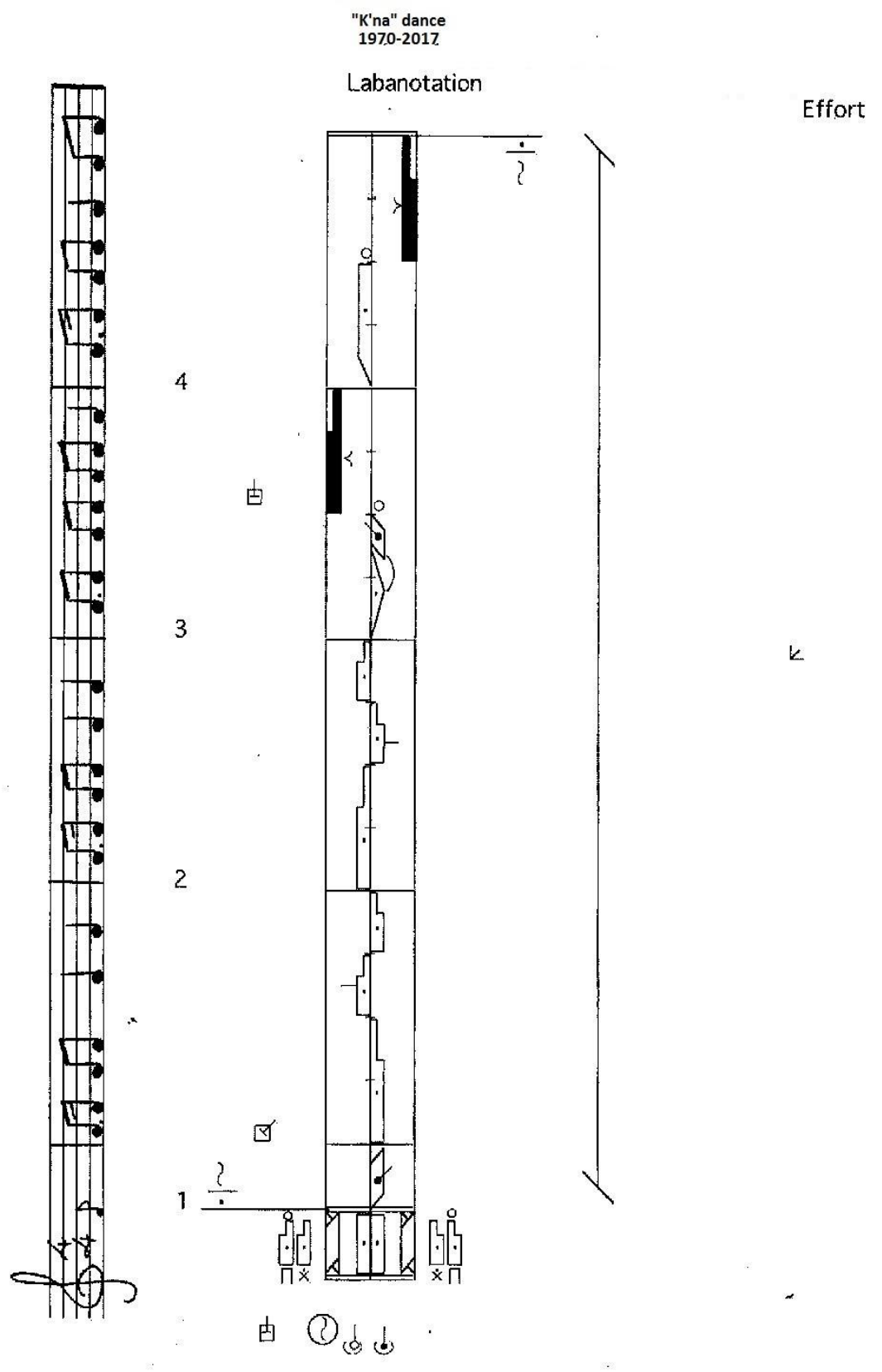

Figure 4: "K'na" dance pattern that proposed by Junta in Thrace (Filippidou, 2018) 


\section{Kina Halayi Edirne}

Labanotation

Effort

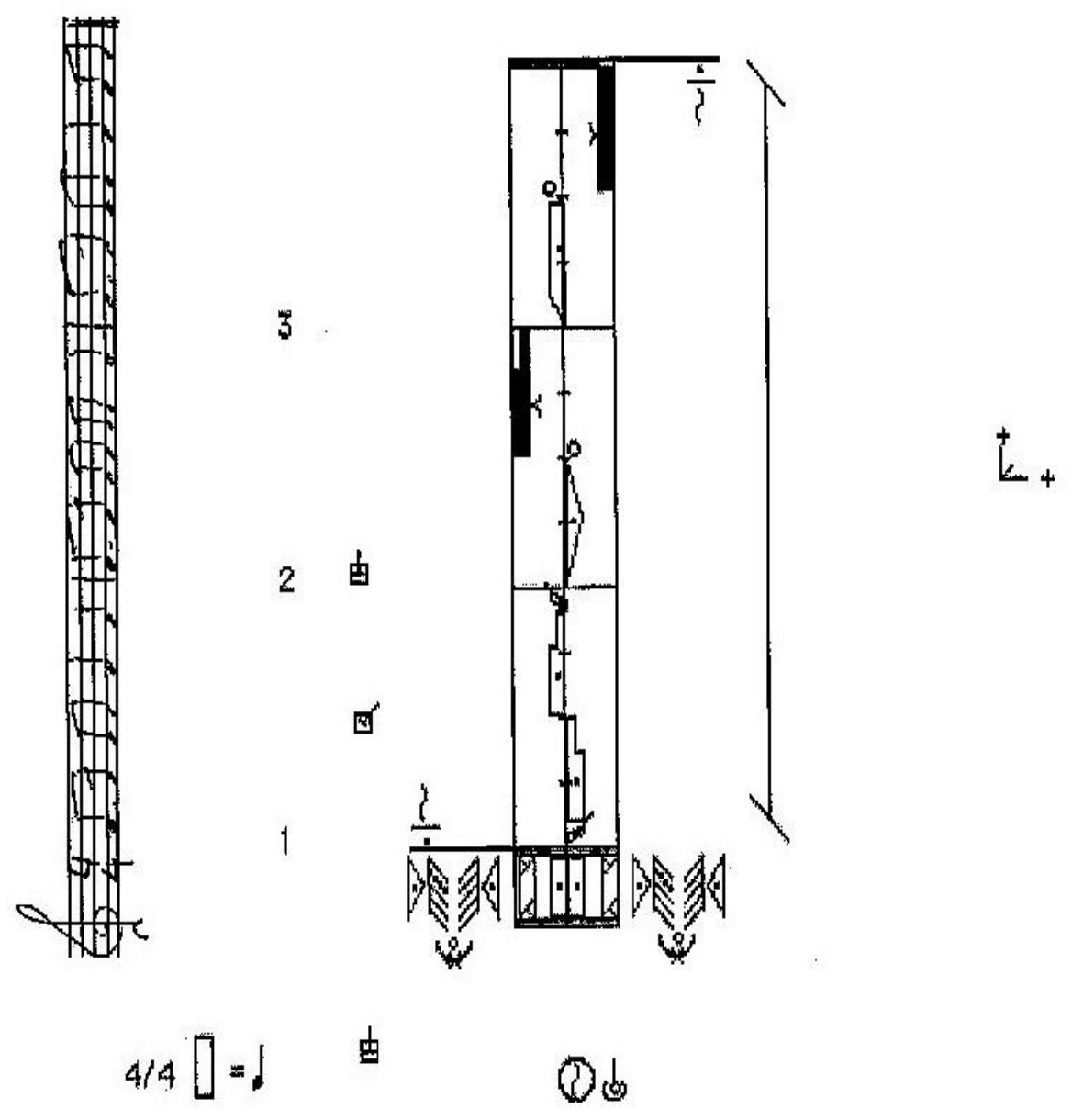

Figure 5: “K'na" dance in Edirne (Filippidou, 2018)

\section{The construction of national identity as a result of the cybernetic tradition of communication}

As mentioned above, the area of Thrace consisted of a great geopolitical unit that was divided into three areas/regions. This division took place due to the geopolitical demarcation of the borders and the subareas/subregions were distributed among three different neighboring countries, namely Bulgaria, Turkey and Greece.

Geographers usually interpret borders as material demarcated on the ground. However, the definition, in other words the demarcation of a material border, is a very difficult task for geographers since it defines and classifies regions (Topaloglou \& Petrakos, 2008). More specifically, in natural geography border demarcation determines regional natural processes such as isotherms in climatological maps or the borders of the geological 
formations, while in anthropogeography (Kourliouros, 2011, Leontidou, 2011) it forms areas of social actions and interests such as property borders or country borders.

Therefore, borders determine geographic borders of political entities or legal jurisdiction such as countries or local administrative regions within a country. They also determine where a community starts from and at what point it ends, thus defining it at the same time. These national and administrative boundaries are consolidated by law, but they are usually determined through natural topography as it is set by a mountain, sea or river, while borders can be formed based on racial, linguistic or religious differences (Topaloglou \& Petrakos, 2008).

The latter also took place in the Thrace area. The Treaty of Lausanne that demarcated borders between Turkey and Greece was based on religious criteria. Therefore, people of Thrace that belonged to Orthodox communities (Roum Mileti) were considered exchangeable and immigrated to the other side of the river Evros. In this way, Evros River bisected Thrace and was named as a border of these two religious groups and by extension, the frontier of these two nations.

This borderline of river Evros is a material, but, also, a symbolic construct. In particular, a "symbolic limit" is the limit one forms in his mind and it differs from a political boundary that is imposed by political force. However, in the area of Thrace these imaginary limits coincide with the political boundaries of the area. Thus, the frontier of Thrace defines the line of "we" and "the others" (Topaloglou \& Petrakos, 2008), introducing discontinuities and delineations of a place, which, before the border demarcation, was continuous and undefined, with common traditions, dances and customs.

Based on the above, the frontier of a country defines what the "ins and outs" are, who "they" are and who "the others" are. It also exerts influence on the awareness of people who live and do business close to it. Therefore, the significance of borders and borderlands plays a determining role in the creation of national ideology (Sahlins, 1989; Wilson \& Donnan, 1998), as well as in the creation of a national identity. A nation highlights its interior homogeneity in accordance and in a dialectical relationship with an urge to stress its distinction, especially its superiority among other nations, mainly the neighboring ones, with which they usually maintain a competitive relation (Nitsiakos \& Mantzos, 2002). Frequently, the defining of a national identity is based on ideology of uniqueness and dominance against the "others" (Topaloglou \& Petrakis, 2008).

This also happened in the area of Thrace where the border demarcation gave rise to hostility between the two regions. They were against the "others", the "enemies", the "foreigners", which were reflected on the discriminations: "us" the "civilized" and the "others" the "barbarians", discrimination which clearly reflects the stereotype of national identity (Lalioti, 2002). This fact was nothing but a figment of the argument regarding the existence of the exterior threat which was employed after the border demarcation and according to which the territorial or cultural integrity of the two sub regions was in risk.

According to Rumley and Minghi (1991), people who live in the borderlands (borderlanders) differ from the rest not only because of the conditions of life and perceptions regarding the neighboring land, but also because of the forms of interaction that they develop with the opposite side. Thus, on both sides of Thrace inferior images were developed of the "others" in order to boost national ideology and by extension each area constructed its own national identity. Up to then both areas shared land, traditions and customs. One of these customs it was that of "K'na" which kept on, although it underwent political rearrangements and prohibitions. That was an indication of how significant the " $\mathrm{K}$ 'na" dance event was in both areas of Thrace as well as the common path they both followed. This path might have ended after the border demarcation, but interaction among everyday people, who for centuries 
relied on the significance of the dance event, even though that significance is materialized on a rather symbolical than a real level.

Nevertheless, in order to create a national identity of a country, the cultural traditions and customs should be strong against cultural traditions and customs of other people or countries. Therefore, the custom of "K'na" and even more its dance had to change so as not to coincide with that of the Turks, reminding everyone of their common course. A major role towards this was played by the junta of colonels that took over Greece from 1967 to 1974, during which a homogeneous "pan-Thracian" musical-dance repertoire was created (Filippidou, 2011), in order to boost the national identity of Greek Thrace and to restrict its diverse ethnocultural particularities, a phenomenon that took place all over Greece (Fountzoulas, Koutsouba, Hapsoulas, \& Lantzos, 2017). As a result, all ethnic-cultural groups of the area, as well as Nea Vyssa, followed the standards of the "K'na" dance that was imposed by the political power of that period (see Figure 6).

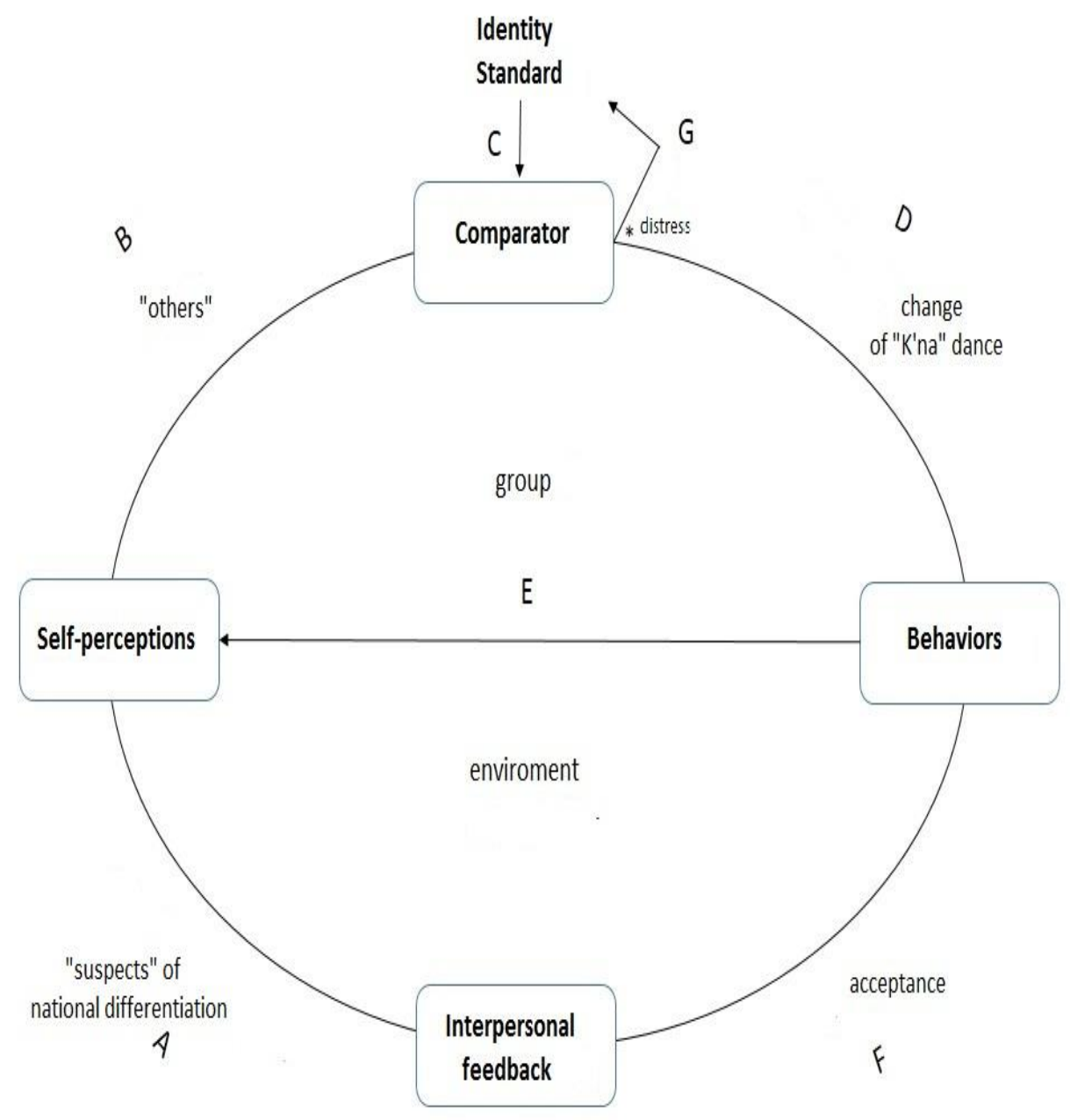

Figure 6: Cybernetic identity control model of Nea Vyssa in response to the opinion of the Junta

(Filippidou, 2018. Adaptation from the model of Burke, 1991)

Therefore, the identity of the people of Nea Vyssa did not remain stable as the residents of this community recognized their differentiation in the dance standards of " $\mathrm{K}$ 'na", 
that the dictatorship of the colonels imposed and changed the choreography of the dance. This occurred because if they had kept the "K'na" patterns they would have been suspected of national differentiation, a fact that was contrary to the identity "standards". In order to fit in and be in harmony with the internal standards of the opinion of "the others", in this case of Greek governance, they changed the choreography of " $\mathrm{K}$ 'na" and adopted the pattern that they proposed. More specifically, the people of Nea Vyssa shunt the first dance phrase of "K'na" (see Figure 2) and use only the second which they had added in the choreography after their arrival in their new homeland (see Figure 3). The second dance phrase which they had embraced by the local communities in order to resemble them with the ultimate aim of identifying their Greek-Thrace identity specified that of the mocked up one of the "panThracian" repertoire (see Figure 4). By doing so, they were considered by "the others" as Greeks of Thrace, a fact that coincided with their own self-perception (Filippidou, 2018).

According to Luhmann (1990), every social system can be influenced by its external environment. In spite of that, it works in an autonomous way. Thus, an identity of a group forms according to interaction among "other" groups but each group develops its own behavior. However, after the end of the junta dictatorship, the inhabitants of Nea Vyssa did not revive the "K'na" dance as it was in its initial form. Instead, they followed the national standard which was imposed. In Turkish Thrace, inhabited by a number of diverse ethnic groups, the "K'na" dance event is a convergence factor as it is performed by the vast majority of these groups. So the dance event of "Kina gecesi", as it was named in Turkish Thrace, is a common point of all these diverse ethnic groups of Turkey and progressively turned into a national symbol. This event, as well as its dance, is a particular symbol of identity which united the people of Turkey into a common feeling and expression of a collective "belonging".

This was more than enough to trigger negative representations to the Greeks of Thrace, notably for those who relocated from the riverfront across Evros, as well as Nea Vyssa. The inhabitants of these communities faced both the feeling of being "the others" when arriving to the area of Greek Thrace as well as being suspected of national identification with the neighboring "enemies", the result of which was their immediate counteraction. Therefore, even though interaction among the people of Thrace of both countries may not be natural or in other words real, in a way that one's behavior might influence the other's behavior, however the members of each group take action again. Dealing with this meant interaction against a very significant symbol on both parts is particularly relevant. This symbol was the "K'na" event and the dance which it was accompanied by. On the one hand this is a national symbol for the Turks and on the other hand of great importance for the Greeks who preserved it in every way they could, in spite of the reactions of "the others".

In order for those traditions not to coincide with the traditions of other populations, let alone the neighboring countries, especially Turkey due to the fact that historically and politically they were never on good terms, the Greeks did not re-establish the " $\mathrm{K}$ 'na" event as it was in its initial form, but they preserved the form of "pan-Thracian" musical and dance repertoire. By doing so, they preserved the identity of the Greek Thrace and not that of a refugee coming from Turkish Thrace that could have been attributed to them in case they insisted in maintaining the common similar choreography of "K'na". Thus, although the influence of the junta on their behavior was no longer existent, the people of Greek Thrace preserved the dance pattern of "K'na" that the junta had proposed to them, as opposed to the dance pattern of the Turkish Thrace people, in order to keep their own identity standard. Besides, as it was aforementioned, the balance within a group does not come automatically, even if its identity standard coincides with the incoming messages of its social environment, but its members keep altering their behavior in such a way that perceptions of "the others" of 
them remain the same (Swann \& Hill, 1982) (see Figure 7).

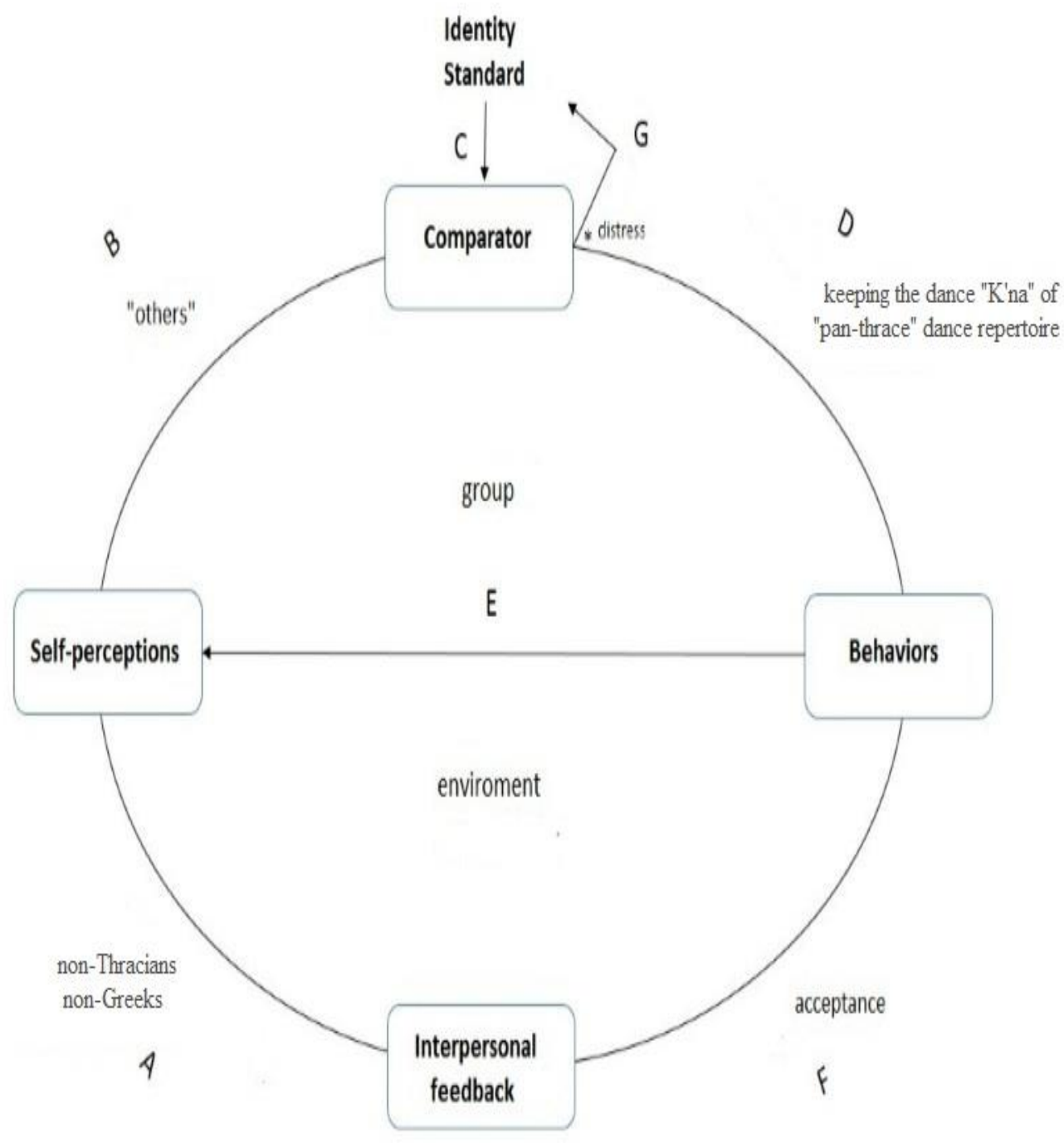

7: Cybernetic identity control model of Greek Thracians

Figure (Filippidou, 2018. Adaptation from the model of Burke, 1991)

Subsequently, Greek Thracians, in order to continue being considered Greek Thracians by "the others" and the messages from their social environment to continue being positive towards them as well as close to their internal standards, they insisted on preserving an afterthought form of "K'na" dance, which was the result of political imposition. This form of the "K'na" dance differed in all aspects of the dance triune, which was also the reason for choosing and preserving it. Apart from its music and Greek song there was also an alteration in the component of movement.

Despite the above, during the latest years, and thanks to the intervention of researchers or dance teachers, the inhabitants of the Greek Thracian communities under study have started dancing the previous "K'na" form on stage. However, although there are still living members who danced this form and it is danced once again, even occasionally, what seems to prevail in the participatory events, in other words when celebrating the " $\mathrm{K}$ 'na" dance event is its "panThracian" form. 
This fact suffices to clearly prove the transnational self-adjustment that took place on both sides against that significant symbol. Consequently, by preserving the "K'na" dance unchanged and recognizing it as a national symbol, the people of Edirne in Turkish Thrace forced the people of Nea Vyssa in Greek Thrace to counteract and retain a different dance form in order to create two separate national identities.

By doing so, both groups self-adjusted, because when one observed the other keeping the dance unchanged, it differentiated it, while the first, observing the diversification of the "other" group insisted on its preservation, in order to keep steady balance within the system. Therefore, through feedback both groups received from the other side of the border, they created self-perception. By comparing this to their identity standard there were results as well as actions. As follows, the Thracian Greeks changed the "K'na" dance so as not to be considered Turks, while on the other hand the Edirne Turks considered it a national symbol and kept it the same (see Figure 8).

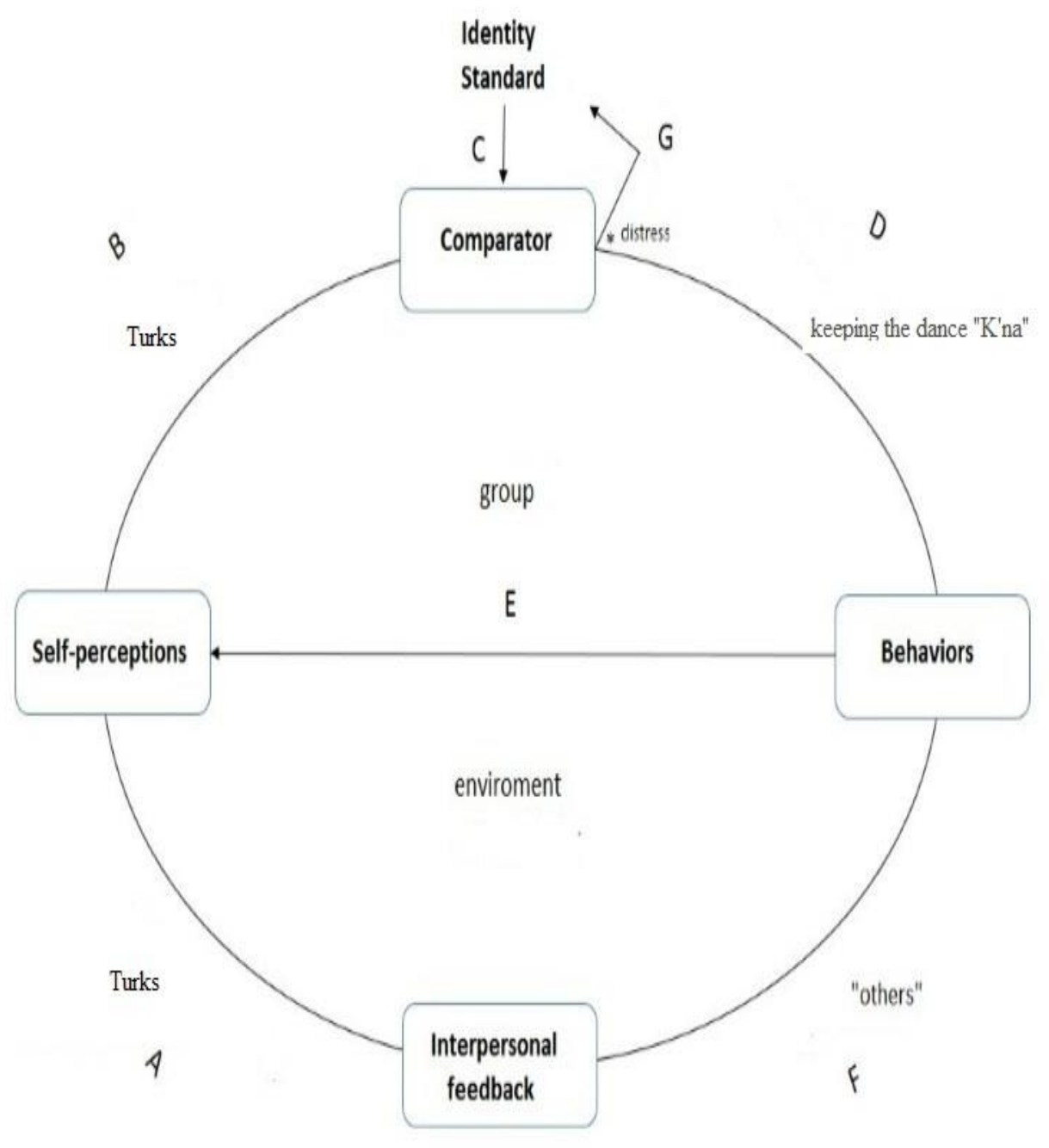

Figure 8: Cybernetic identity control theory model of Edirne Turks 


\section{Conclusions}

This paper studies the cybernetic construction of national identity within the background of the wedding dance event of "K'na" as it takes place in the communities of Nea Vyssa and Edirne, in Greek and Turkish Thrace respectively. In order to do this as well as to look at the theoretical issues arising from it, a combination of two parameters was used. First, the sociocybernetic approach was adopted as a theoretical point of view, as thus is defined through Burke's theoretical model (1991). Secondly, the analysis and study of the "K'na" dance itself was considered as a condition so as to examine the theoretical issues. This combination of parameters, the notation and analysis of the dance itself on one hand, as well as the analysis and interpretation based on the theoretical model of Burke (1991) on the other hand, was the basic structure of this paper, providing a holistic approach towards dance research.

Additionally, in this paper dance was perceived as a symbol and a "container" of meaning that can be used, inter alia, as a means of action and counteraction to the feedback people receive by "the others". Thus, dance in this paper is perceived as an indicator of the "construction" of this identity, a characteristic of dance that is attributed to its polysemy (Giurchescu, 1994, 2001), but, also, to its ability to communicate information in a non-verbal way (Koutsouba, 2003; Lange, 1980). In turn, this allows the development of symbolic deductions and the production of "cultural knowledge" at the same time (Sklar, 1991).

From the data analysis, it is showed that the dance of " $\mathrm{K}$ 'na" forms and reforms the ethnic and national identity of the groups who use them in order to react to the messages they receive via the communication with "the important ones" or "the national others". In this way, by readjusting the dance of "K'na" in conjunction with the reactions of "the important ones", both national groups self-adjust the perceptual input they receive in order to balance their interior "standards" with the appraisals of the "others" for "themselves".

On the other side, in the Turkish Thrace, the "K'na" event and, by extension, its accompanying dance, was converted into a national symbol after uniting all the ethnic groups co-existing in Turkey. From this moment on, the "K'na" dance event was proclaimed as "our" dance in Turkey and it was an indicator of the national identity to the "other nationals". This incident forced the "other nationals" in other words, the Greeks, to preserve the "panThracian" form that was imposed by the junta even after its downfall, in order to validate their diversity against "the others", meaning the Turks, and therefore to continue being considered as Greeks of Thrace.

Therefore, the theoretical model of Burke (1991) is found to be accurately applicable in studying the identity of these two ethnic groups in the wider Thrace region, displaying its validity not only regarding individual identity but also collective identity. Even though the above model had not been used to date in dance studies, however, through the example of the event of the "K'na", as this is performed by communities of Greece and Turkey under study, it proved to be applicable in that field as well. Combining the analytical tools of the dance with this identity control model gives us the possibility to investigate issues of construction and reconstruction of the collective identity of a group, which constitutes a "structure" resulting from a process of communication and interaction with "other" groups.

In conclusion, it can be argued that "belonging" is an active and continuous process that allows the members of a group to act and exchange the meanings of their actions as reactions to the messages they receive in their environment. Hence, the "construction" of an identity results from a continuous procedure of self-regulation and self-control establishing that the construction of the identity is a cybernetic process. 


\section{REFERENCES}

Adshead, J., \& Layson, J. (eds.). (1986). Dance history. A methodology for study. London.

Buckland, Th. J. (1999). Introduction: Reflecting on dance ethnography. In T. Buckland (Ed.), Dance in the Field. Theory Methods and Issues in Dance Ethnography, (pp. 1-10). Great Britain: Macmillan Press Ltd.

Burke P. J. (1991). Identity processes and social stress. American Sociological Review, 56, 836-849.

Burke P. J. (1991b). An identity theory approach to commitment. Social Psychology Quarterly, 54, $239-251$.

Burke P. J. (1995). Identities and self-verification in the small group. Social Psychology Quarterly, 58, 61-73.

Burke P. J. (1996). Social identities and psychosocial stress.In H. Kaplan (eds.), Psychosocial Stress: Perspectives on Structure, Theory, Life Course, and Methods. Orlando, FL: Academic Press.

Burke P. J. (1997). An identity model for network exchange. American Sociological Review, 62, 134-150.

Burke, R. J. \&. Cooper, C. L. (2000). The organization in crisis: Downsizing, restructuring, and privatization. Oxford: Blackwell Publishers.

Burke, P. J. \& Freese, L. (1989). Identity and social structure. Annual meeting of the American Sociological Association. San Francisco, CA.

Burke, P. J. \& Gecas, V. (1994). Self and identity. In K. Cook, G. Fine, \& J. (eds.), House Sociological Perspectives on Social Psychology. Boston: Allyn and Bacon.

Burke, P. J. \& Reitzes, D. C. (1981). The link between identity and role performance. Social Psychology Quarterly, 44, 83-92.

Burke, P. J. \& Stets, J. (1994). Inconsistent self-views in the control identity model. Social Science Research, 23, 236-262.

Burke, P. J. \& Tully, J. (1977). The measurement of role/identity. Social Forces, 55, 881-897.

Burke, W. W. (1980). Systems theory, gestalt therapy, and organization development. In T.G. Cummings (eds), Systems Theory for Organizational Development, (pp. 20 222. New York: Wiley-Interscience.

Chatzopoulos, K. (2015). The integration of Thrace in Greece. In M. Dimassis, P. Valsamidis, I. Bakittzis, A. Papazoglou, \& A. Nisam (eds.), Representations and Separations (pp. 411-418). Komotini: Democritus University of Thrace, School of Classical and Human Studies.

Chilari, A. (2009). Local and national identity in motion: The example of Tsakonikos dance in Leonidio Arcadia. Unpublished postgraduate dissertation. Athens: TEFAA University of Athens.

Cowan, J. (1998). Idioms of belonging: Multilingual (co) localization of local identity in a Greek community in Macedonia. In D. Gefou-Madianou (ed.), Anthropological theory and Ethnography. Modern trends (pp. 583-618). Athens: Ellinka Grammata

Dimopoulos, K. (2011). Components of the field and gendered dance practices. The lowland and mountainous communities of Karditsa Thessaly and the period 1920-1980. Master thesis. Athens: Department of Physical Education and Sport Science, National Kapodistrian University of Athens.

Dimopoulos, K., Tyrovola, V. \& Koutsouba, M. (2009). The end of a ritual or the beginning of new social structures? The case of Bright Tuesday in the community of Lazarina, Karditsa, Thessaly. In Proceedings of the 23rd World Congress on Dance Research (pp. 1-6). Malaga: International Dance Council-CID

Dimopoulos, K. (2017). Timeless and synchronous processes in the "game" of gender identity construction. Dance and gendered transformation in the community of Megala Kalyvia, Trikala, Thessaly. PhD thesis. Athens: Department of Physical Education and Sport Science, National Kapodistrian University of Athens

Ellestad, J. \& Stets, J. E. (1998). Jealousy and parenting: Predicting emotions from identity theory. Sociological Perspectives, 41, 639-668.

Erixon, S. (1967). Urgent-ethnological tasks. Ethnologia Europaea, 1,163-169.

Filippidou, E. (2010). Recycling the tradition: The dance in Nea Vyssa, northern Evros. Alexandroupolis: Municipality of Vyssa.

Filippidou, E. (2011). Dance and identity search. Acculturation and retribalization strategies of Inoi Gkagkavouz in Evros. Master thesis. Athens: University of Athens, Department of Physical Education and Sport Science.

Filippidou, E., Koutsouba, M. \& Tyrovola, V. (2013). Interweaving dance, ritual and identity: The dance at the "k'na" ritual as a reference point for the formation of the local cultural identity at the Greek region of Evros. Science of Dance, 6, 19-40. Available at http://www.elepex.gr/images/stories/ektostomos/filippidou-kna-full-text-gr.pdf.

Filippidou, E. (2018). Crossing the borders, uniting the people. Cybernetic dance approach at the " $k$ 'na" Thracian wedding event in Greece and Turkey. $\mathrm{PhD}$ thesis. Athens: University of Athens, Department of Physical Education and Sport Science. 
Fountzoulas, G. (2016). Dance and politics: Positions and contrasts in the dance event "Gaitanaki" in Skala and in Dafni, Nafpaktia Greece. Master thesis. Athens: TEFAA University of Athens.

Fountzoulas, G., Koutsouba, M., Hapsoulas, A. \& Lantzos, V. (2017). The transformation of the intangible cultural heritage of dance through state education and politics in the ritual of a rural Greek community. Mediterranean Journal of Social Sciences, 8(1), 243-251. Available at http://www.mcser.org/journal/index.php/mjss/article/view/9687/9326.

Geertz, C. (2003). Thick description: Toward an interpretive theory of culture. In C. Geertz (ed.), The interpretation of cultures. Selected essays (pp. 1-30). New York: Basic Books

Gefou-Madianou, D. (1999). Culture and ethnography. From ethnographic realism to political criticism. Athens: Ellinika Grammata.

Giurchescu, A., \& Torp, L. (1991). Theory and methods in dance research: A european approach to the holistic study of dance. Yearbook for Traditional Music, 23, 1-10.

Giurchescu, A. (1994). The Power and the Dance Symbol and its Sociopolitical Use. In I. Loutzaki (ed.), Dance and its Socio-Political Aspects. Dance and Costume, Proceedings from the 17th Symposium of the Study Group on Ethnochoreology (pp. 15-23). Nafplion: Peloponnesian Folklore Foundation \& International Council for Traditional Music.

Giurchescu, A. (2001). The power of dance and its social and political uses. Yearbook for Traditional Music, 33, 109-121.

Greek parliament. (2000). Thrace 2000, 80 years of integration with Greece. Athens

Holt T.R., \& Turner, E.J. (eds.). (1972). The methodology of comparative research. New York: The Free Press.

Hutchinson, A. (1977). Labanotation. The system of analyzing and recording movement. London: Dance Books.

Kalogeropoulou, S. (2013). Greek dance and everyday nationalism in contemporary Greece. Master dissertation. New Zealand, School of Physical Education, Sport and Excersice Sciences. University of Otago.

Koutsouba, M. (1991). The Greek Dance Groups of Plaka: A Case of “Airport Art”. M.A. dissertation. Guildford: Department of Dance, University of Surrey.

Koutsouba, M. (1997). Plurality in motion: Dance and cultural identity on the Greek Ionian Island of Lefkada. Ph.D. thesis. London: University of London.

Koutsouba, M. (1999). "Outsider" in an "inside" world, or dance ethnography at home. In T. Buckland (ed.), Dance in the Field: Theory, Methods and Issues in Dance Ethnography (pp. 186-195). London: Macmillan Press.

Koutsouba, M. (2003). Identity and anthropological aspects of traditional dance. In N. Giftulas and others. (ed.), Arts II: Overview of Greek music and dance: Greek dance practice: traditional dance (Volume E, pp. 33-45). Patras: Hellenic Open University

Koutsouba, I.M. (2005). Notation of dance movement. The passage from prehistory to the history of dance. Athens: Propobos.

Koutsouba, M. (2014). Places, dance(s) and 'realities'. Contexts and dance forms of Tsamikos dance in Greece. In E.I. Dunin \& C.E. Foley (eds.), Dance and Place \& Dance and Festival, Proceedings of 27th Symposium of the International Council for Traditional Music (ICTM) Study Group on Ethnochoreology (pp. 99-106). Ireland: The Irish Academy of Music and Dance, University of Limerick.

Lalioti, V. (2002). Social memory and ethnic identity: Ancient Greek drama performances as commemorative ceremonies. History and Anthropology, 13(2), 113-137.

Lange, R. (1980). The development of anthropological dance research. Dance Studies, 4, 1-36.

Leonidou, L. (2011). A geographic country. Greek idols in the epistemological reflections of European geography. Athens: Propobos.

Littlejohn, S.W. \& Foss, K.A. (2012). Human communication theories. Athens: Pedio.

Luhmann, N. (1990). Essays on Self-Reference. N.Y.: Columbia University Press.

Lydaki, A. (2001). Qualitative methods of social research. Athens: Kastaniotis.

Manos, I. (2002). Visualizing culture - demonstrating identity: Dance performance and identity politics in a border region in northern Greece. Germany: Universität Hamburg.

Margaris, Z. (2004). L' Immigration Albanaise en Grece. Danse et indentification. PhD Thesis. Paris: Université Paris 8.

McQuail, D. \& Windahl, S. (1993). Communication Models for the Study of Mass Communication. London: Longman.

Nitsiakos, V. \& Mantzos, K. (2002). Civilizing the tradition: Uses of polyphonic songs in Greece and Albania. At the Scientific Symposium, The Present of the Past: History, Folklore, Social Anthropology (pp. 131147). Athens: Society for Studies of Modern Greek Culture and General Education.

Ogurchov, PA (1983). Comparative-historical method. In the Great Soviet Encyclopedia, (pp. 298-299). Athens: Akadimos. 
Parliamentary Papers, Great Britain, Turkey No 1. (1923). Lausanne Conference en Near East Affaires 19221923, Records of Proceedings and Draft Terms of Peace. London, 817.

Paschalidis, G. (2000). Cultural identity as a right and a threat. The dialectics of identity and the ambivalence of criticism. In Ch. Konstantopoulou, L. Maratou-Alibranti, D. Germanos, \& Th. Economou (Ed.), "We" and "Others". Reference to Trends and Symbols (pp. 73-83). Athens: Typothito.

Panopoulou, K. (2001). The dancing identity of the Vlachs of Serres. PhD Thesis: Department of Physical Education and Sport Science, Serres. Aristotle University of Thessaloniki.

Papakostas, Ch. (2007). Dance-musical identity and otherness: The case of the Roma of Herakleia in the prefecture of Serres. PhD Thesis. University of Thessaly.

Rumley, D. \& Minghi, J.V. (1993). The Geography of border landscapes. New York: Routledge.

Sarakatsianou, Z. (2011). National groups and dance practices in Stenimachos, Imathia, Macedonia. The custom of Saint Tryphon as an indicator of local cultural identity. Unpublished postgraduate dissertation. Athens: TEFAA, University of Athens.

Sklar, D. (1991). On dance ethnography. CORD Dance Research Journal , 23(1), 6-10.

Stets, J. E. (1995). Modelling control in relationships. Journal of Marriage and the Family, 57, 489-501.

Stokes, P. (2006). Identity: articulating cybernetics and sociology. Kybernetes, 35 (1/2) pp. 124- 147.

Stokes, P. A. (2007). From management science to sociology: Cybernetics, finalization and the possibility of a social science. Kybernetes,. 36(3/4), 420-436.

Stocking, G. (1992). The Ethnographer's magic and other essays in the history of Anthropology. Madison: The Univervity of Wisconsin Press.

Swann, W. B. \& Hill, C. A. (1982). When our identities are mistaken: Reaffirming self conceptions through social interaction. Journal of Personality and Social Psychology, 43, 59-66.

Thompson, P. (2002). Voices from the past: Oral history. Athens: Pletron.

Topaloglou, L. \& Petrakos, C. (2008) Attitudes and perceptions of the border for the initial conditions of crossborder interaction: Problem or advantage. Research Series, 14 (7), 119-142.

Vrizas, K. (2005). Global communication. Political Identities. Athens: Gutenberg.

Watzlawick, P., Beavin, J. H., \& Jackson, D. D. (1967). Pragmatics of human communication: A study of interactional patterns, pathologies, and paradoxes. New York: Norton.

Wilson, M. T. \& Donnan, H. (1998). Nation, state and identity at international borders. In Border Identities. Nation and State at Intrnational Frontiers. Cambridge: Cambridge University Press. 